\title{
REFLEXIONES DEL SER DOCENTE: UNA EXPERIENCIA DE VIDA EN CONSTRUCCION PERMANENTE - DIALOGANDO CON PAULO FREIRE
}

\author{
REFLECTIONS OF THE TEACHING BEING: AN EXPERIENCE OF LIFE IN \\ PERMANENT CONSTRUCTION - DIALOGUE WITH PAULO FREIRE \\ REFLEXÕES DO SER DOCENTE: UMA EXPERIÊNCIA DE VIDA EM CONSTRUÇÃO \\ PERMANENTE - DIÁLOGO COM PAULO FREIRE
}

Resumen: Me preguntaba, ¿Qué aporte puede dar estos relatos de mi vida para repensar la educación? Entonces recibí el veredicto para ser publicado con observaciones maravillosas de un evaluador, que resumo. Es una reflexión de la esencia de mi realidad experimentada en la construcción de la práctica docente universitaria en un diálogo con la teoría que subyace en las palabras de Paulo Freire. Es una contribución significativa para la construcción del conocimiento sobre la práctica y formación docente, desde la discusión y reflexión de la dimensión humana y, en particular de la enseñanza en la educación superior. Un documento para ser compartido con docentes y aquellos en iniciación científica. Muestro una articulación entre la enseñanza, la investigación y la extensión que ha tenido lugar en mi práctica social, y enfrentamiento a las dificultades de la educación contemporánea. Muestro la desconstrucción y construcción en la profunda relación existencial y social de mi opción de ser docente.

Palabras clave: Paulo Freire. Formación docente. Historia de vida. Extensión.

\footnotetext{
Abstract: I was wondering, what contribution can these stories from my life make to rethink education? Then I received the verdict to be published with wonderful comments from an evaluator, which I summarize. It is a reflection of the essence of my reality experienced in the construction of university teaching practice in a dialogue with the theory that underlies the words of Paulo Freire. It is a significant contribution to the construction of knowledge about teacher practice and training, from the discussion and reflection of the human dimension and, in
}

particular, of teaching in higher education. A document to be shared with teachers and those in scientific initiation. I show an articulation between teaching, research and the extension that has taken place in my social practice, and confronting the difficulties of contemporary education. I show the deconstruction and construction in the deep existential and social relationship of my choice to be a teacher.

Keywords: Paulo Freire. Teacher training. Life history. Extension.

Resumo: Fiquei pensando: que contribuição essas histórias de minha vida podem dar para repensar a educação? Em seguida, recebi o veredito a ser publicado com comentários maravilhosos de um avaliador, que resumo. É um reflexo da essência da minha realidade vivida na construção da prática docente universitária em diálogo com a teoria subjacente às palavras de Paulo Freire. É uma contribuição significativa para a construção de conhecimento sobre a prática e a formação de professores, a partir da discussão e reflexão da dimensão humana e, em particular, do ensino na educação superior. Um documento a ser compartilhado com professores e iniciantes científicos. Mostro uma articulação entre o ensino-pesquisa-extensão que ocorreu na minha prática social e o enfrentamento das dificuldades da educação contemporânea. Mostro a desconstrução e a construção no profundo relacionamento existencial e social da minha opção de ser docente.

Palavras chave: Paulo Freire. Formação de professores. História de vida. Extensão. 


\section{Introducción}

Ser maestro es el máximo nivel para alguien que dedique su vida a educar, trascender de ser profesor y docente, para dejar huellas en otros, en la vida. Un privilegio que llena el alma. Así como cada ser es único, así cada docente lo es, con un cúmulo de experiencias que contar que se reservan en la mente, se transforman en la expresión de la praxis diaria.

Me propuse este escrito por la reflexión lograda en una disciplina de post-graduación de Educación Ambiental en la Universidad Federal de Rio Grande, Brasil; cuando discutíamos la crisis en la formación docente. Concluíamos que cada docente tiene una historia que contar, muchas veces se siente solo con sus problemas y ahogado en sus experiencias. Y como dicen Branda y Posta (2017, p. 65)

En su rol de alumnos, los docentes aprendieron a enseñar, a ser maestros y a relacionarse con la escuela. En cada práctica hay un aprendizaje explícito que se manifiesta en un contenido o en una habilidad, pero la experiencia en la que se despliega ese aprendizaje deja una marca profunda que se transforma en aprendizaje implícito.

Asumo entonces que las historias de vida son una forma de expresión reconocida en el mundo intelectual, con valor para la trascendencia de la experiencia y el pensamiento. Sobre mi historia mantengo una postura crítica, considerando que es inacabada, en construcción permanenteenlatemporalidad quemepertenece, aprenderé hasta el día de mi muerte. Al respecto de historias de vida de docentes Goodson (2003) muestra la importancia para el hacer pedagógico y los cambios educativos, por estar llenas del ser práctico, social y político,

[...] también nos permitiría observar mejor al individuo en relación con su contexto histórico; al poner de manifiesto la intersección entre su historia y la de la sociedad, y ver bajo una nueva luz el abanico de elecciones, contingencias y opciones que se abren para el individuo (GOODSON, 2003, p. 753).

Igualmente, en estos días han surgido otras provocaciones, por enfrentarme a un espacio académico y regional, donde Paulo Freire es el alma del discurso pedagógico. Así entonces he sido confrontada, por varias
* Profesora Visitante Extranjera en el Programa de Postgrado en Educación Ambiental (PPGEA) en la Universidad Federal de Rio Grande. Doctora en Educación Ambiental. Ex-profesora Titular del Decanato de Agronomía de la Universidad Centroccidental Lisandro Alvarado (UCLA/Venezuela).

E-mail: careliahidalgo@gmail.com. 
personas en mi actual temporalidad, diciendo "no refieres a Freire, pero lo que dices y has hecho es de él". Entonces en este espacio de tanta expresión del famoso educador popular, decidí dialogar mi historia de vida como docente con él, en las diversas temporalidades que me construyen.

En el sentido ontológico entiendo mi trascendencia, como la expresa Kant o la filosofía primera que hablo Aristóteles, al considerar mi esencia. Henry (2015) refiere en el escrito "La esencia de la manifestación", que

El hombre mismo, la vida en él, no se debe interpretar como un ente en el interior del horizonte del ser, sino como la esencia misma a partir de la cual el ser, en su diferencia respecto de los entes, se proyecta y se funda. (HENRY, 2015, p. 5).

Así entonces develo mi esencia que trasciende en las subjetividades de mí ser, en temporalidades que permitieron relaciones con los entes trascendentes que determinan mi ser actual, en continua transformación. Esta introspección sobre mi ser docente quizás siempre ha estado latiendo en mi mente, pero fue activada como hoy, en tres momentos clave de mi existencia. Momentos que recuerdos con mucha reflexión, fueron: la pregunta sobre "qué era la realidad para mí" formulada por García ${ }^{1}$ en el 2008; otra cuando fui elegida para una entrevista como educadora ambiental por parte de Álvarez ${ }^{2}$ en el 2009; y la pregunta sobre mis esencias y gustos para presentarme en un conversatorio por parte de Coello ${ }^{3}$ en el 2014. Pero son mis poesías ${ }^{4}$, la expresión de reflexiones de mí ser interior conectado con la vida.

La esencia, de mi ser trascendente, la presentó con raíces de mi temporalidad que ha transcurrido geográficamente en 19 mudanzas de morada, en 3 países: Chile quien me vio nacer, donde se fundaron mis valores y ser político; Venezuela quien me hizo profesional con un sinfín de oportunidades, me inculcó gran amor hacia ella; y Brasil quien me cobija hoy como Profesora Visitante Extranjera en la Universidad Federal de Rio Grande, gracias al reconocimiento de mi trayectoria profesional como educadora ambiental. Luego de escribir esto, veo como Freire (1991) al prepara un escrito sobre "La importancia del acto de leer", habla sobre la necesidad de "[...] "releer" momentos de mi práctica, guardados en la memoria, desde las experiencias más remotas de mi infancia, de mi adolescencia, de mi juventud, en que la importancia del acto de leer se vino constituyendo en mí" (FREIRE, 1991, p. 1).

Es que releo tantos recuerdos como si fueran películas nítidas de las bellezas observadas, disfrutadas; pero también otros tantos grises y tristes de la humanidad
1 Margarita García la conocí como autora del Libro Azul de Educación Ambiental de la Universidad Pedagógica de Caracas, luego como coordinadora del Doctorado en Educación Ambiental de la misma institución fue mi profesora de Filosofía de la Educación y luego mi tutora de tesis Doctoral. Actualmente jubilada.

2 Alejandro Álvarez creador del Foro de Educación Ambiental Tuqueque, fue mi profesor de Fundamentos de Educación Ambiental en mi maestría, entrevista: Educadores Ambientales de Venezuela (La gente que está trabajando para hacer un mejor país) 4 - Carelia Hidalgo Disponible en: https://forotuqueque. blogspot.com/2009/09/

3 José Luis Coello en aquel momento Director del Parque Bararida celebró el Día Mundial de la Tierra con "Ideas verdes para un planeta azul”. Disponible en: http://parque-bararida.blogspot. com/2014/04/.

4 Publicadas las de este último año en Instagram @careliarayenhidalgo. 
percibida y vivida, que provocaron tantos cambios que me hicieron perder el arraigo y la identidad con un único territorio; por eso aprendí a disfrutar cada lugar donde me encuentro. En ese placer de observar la naturaleza en su esplendor y a los entes que me han rodeado, tal como dice Freire "re-creo, re-vivo, la experiencia vivida en el momento en que todavía no leía la palabra"; allí encuentro unas vacaciones inolvidable con mi abuela y primas. También se recrean las leyendas que fueron clavadas con la enseñanza del miedo, al escuchar cuentos terroríficos en tertulias familiares. Mi temor fue morir por una espina de pescado clavada en algún lugar de mi sistema digestivo; pero mi gusto por el pescado pudo más que el miedo, fue superado por horas en una mesa finalizando la comida, no acepto el miedo que paraliza. Solo arriesgando logramos avanzar, o retroceder para avanzar con experiencia hacia los sueños, como dice Freire y Shor (1986)

Sentir medo é uma manifestação de que estamos vivos. Não tenho que esconder meus temores. Mas, o que não posso permitir é que meu medo seja injustificado, e que me imobilize. Se estou seguro do meu sonho político, então uma das condições para continuar a ter esse sonho é não me imobilizar enquanto caminho para sua realização. $\mathrm{E} o$ medo pode ser paralisante. (FREIRE; SHOR, 1986, p. 39).

Relato momentos que me formaron como docente, iniciando con los recuerdos de infancia que formaron mis valores en una familia luchadora y una escuela pública. En ese transcurrir de una infancia feliz jugando, también me comenzó a acompañar la lectura en conexión con mi padre y con el mundo. En esos mismos caminos temporales se forjó mi pensamiento político que se activó en mi juventud, se transformó por las circunstancias vividas y se manifiesta en mi praxis educativa entrelazada con la educación ambiental y la agroecología. A pesar de esa aparente timidez que un día me marco, mis compañeros de educación media me apodaron la muda, el liderazgo también ha sido parte de mí ser educativo. En ese impulso de arriesgarme he liderado en el transcurrir de mi vida, algunas acciones que me enseñaron, allí fui aprendiendo que el liderazgo con el reconocimiento de las habilidades de cada uno permite el éxito. La primera experiencia fue a mis nueve años con un club de juego; en mi inicio universitario la fundación del Centro Demostrativo de Tecnologías Agroecológicas (CenecoAgro); el impulso para la creación de la Comisión de Ambiente de la Universidad Centroccidental Lisandro Alvarado $^{5}$; en esa misma gestión ambiental universitaria 
logramos crear la Red Venezolana de Universidades por el Ambiente (REDVUA) ${ }^{6}$.

En cada paso de vida también estaba la búsqueda de la conexión con la existencia en un sentido inmaterial más allá de lo tangible, donde el amor es la expresión de esa espiritualidad que me calma, en eso es el amor la clave en el enseñar para aprender. En ese transcurrir también fui tomando caminos para alcanzar mi formación académica donde se fue forjando el ser docente. Fue la práctica diaria con la gente que me hizo humana, ha sido el contacto con otros, en un diálogo de saberes, donde ocurren continuamente cuestionamiento y preguntas, bases del compromiso docente. El docente comprometido se encuentra en formación permanente, de lo contrario es una simple grabación y acto mecánico de entregar conocimientos.

Luego de iniciar la escrita de esta parte de mí ser, por razones meramente estructurales de publicación decidí sacar varios tópicos que son extensos, tales como mis experiencias con currículo y formación docente que pretendo también expresar en otro escrito. Entonces, este es un documento inacabado que me permitió pensarme y rehacerme, en el releerme con mucha alegría.

\section{La educación formal básica, en Chile}

La educación requiere enseñar valores, como la disciplina y solidaridad; así como respetar las diferencias con otros para hacer los recuerdos felices. Siempre existirán docentes que nos marcan, esperemos que sea en amor.

Los niños de los años 60-70 fuimos formados por rígidos métodos de exigencias sobre el conocimiento disciplinar y la conducta social unificada, algo que aún no ha cambiado mucho. A pesar de todas las críticas que pueda recibir la educación de aquella época, para mí, ir a la escuela fue felicidad. Mis pasos iniciales en la escuela fueron a los dos años de edad (1968), por ser compañía de mi madre en sus años de parvulario en Maipú. Me inicié muy precoz en la lectura y números, aun cuando al año tuve retrocesos por causa del nacimiento de mi hermana, celos legítimos de un niño. En ese sentido, por mis habilidades adquiridas, le informaron a mi madre que debía llevarme a una escuela de niños "superiores", a lo cual ella astutamente dijo que sería para crear una desadaptada social, mejor continuaba integrada a la normalidad del mundo. La igualdad rígida, en la educación de aquellos días, me recuerda una colchoneta lila oscuro con flores blancas donde era obligada a dormir en las tardes; hábito que nunca adquirí, solo la adolescencia
5InformacióndelaComisióndeAmbiente en la Universidad Centroccidental Lisandro Alvarado https://www2. ucla.edu.ve\%2Fblog\%2F\%3 Fwpbdp_ listing \% 3 D c o m i s i o n - d e ambiente\&usg=AOvVaw3g_H Czt4bcorPh1_CMlt5

6 Publicación de la Red en el año 2017, sobre el análisis de indicadores de sostenibilidad universitaria, como Capítulo Venezuela: Ambiente y UniversidadesSostenibles.https://www. dropbox.com/s/c3cmp6slh29yobq/ RISU_VZLA_2017\%20.pdf?dl=0 
la venció en su paso. Castigos de un sistema educativo castrante de las individualidades de los niños. Rejas verdes eran la espera ansiosa por el rescate de ese lugar donde mi madre nos dejaba para acudir a sus labores; situación aún vigente que se debate, entre el cuidado del niño y el trabajo de los padres. Esta etapa hasta mis cinco años fue en casa de mi abuela en la población Los Nogales de clase baja, obrera y de luchas sociales. Algunos pocos recuerdos como: el terremoto registrado el 8 de julio de 1971; unas vacaciones con mi abuela y primas, sin mis padres; el funeral de mi bisabuela pasando por la calle; la carreta y animales de los vecinos del frente; mi primera caída que dejó la cicatriz de mi mentón.

Continué mi etapa de formación primaria en una escuela pública para aquella época la $\mathrm{N}^{\circ} 127$ actualmente Escuela Básica Fray Camilo Henríquez, a 16 cuadras de la nueva casa en una población también obrera. Amé a mi maestra Juany, que por cinco años fue parte de mi formación, asunto nada recomendable por los vínculos afectivos que se creaban entre los niños y los docentes. Con ella tuve mi primera experiencia de lección con "sangre", fue sobre la responsabilidad, para nunca olvidar las cosas solicitadas. No fue el castigo físico (coscorrón) lo que me aleccionó, fue la vergüenza que sentí. Olvidé por tercera vez la firma de mi madre sobre una comunicación, mecanismo de diálogo entre la escuela y los padres; hoy existen los whatsapp entre padres y docentes. La reprensión bien dosificada y oportuna, sin maltrato físico no causa traumas, enseña en ciertos momentos. También como docente pienso que la comunicación con los padres es fundamental, incluso en la universidad por los casos especiales a los cuales nos enfrentamos.

En la escuela aprendí a cuidar sus espacios, a valorar la colaboración hacia ella, el trabajo voluntario. Era un país pobre donde las escuelas públicas estaban limitadas en los recursos, entonces los niños teníamos labores diferenciadas al tiempo de estudio para colaborar con ella. En ese contexto fui responsable del jardín del salón de clases y también de llevar la lista de colaboración con botellas y periódicos de rehúso que los niños entregaban en la escuela. También recuerdo mucho las actividades culturales, bailando y realizando composiciones, tengo que reconocer que me gusta bailar, fue mi diversión en mi juventud. Elaborar mapas y pintar me gustaba, aprendí con la gran cantidad de mapas que eran asignados. De esta época también quedó grabada mi primera visita al Museo Nacional de Historia Natural de Chile $^{7}$ y la primera visita a la Biblioteca Nacional ${ }^{8}$, actividades escolares inolvidables,
7 Aun ahí está la ballena y su historia que también ha cambiado http://mnhn. gob.cl/sitio/

8 Una asignación de la escuela, mi primera vez sin padres en micro (ómnibus) con los compañeros, una hazaña. http://www.bibliotecanacional. 
hasta hoy recreo con claridad el tema sobre el primer viaje a la luna y la vida de las ballenas.

En mi quinto año escolar fui seleccionada y reconocida con un diploma del Rotary Club como mejor compañera, no recuerdo como era buena compañera, hoy tampoco me considero la mejor amiga. Sin embargo, recuerdo que en algún momento daban desayunos, me encantaban unas galletas muy duras de avena con una leche espesada con harina, más de una vez regalé mi desayuno a un compañero muy pobre, Luis. Un acto de solidaridad, que mi madre festejaba.

Fue una etapa interesante, entre el tiempo de Unidad Popular (UP) 9 y luego dictadura ${ }^{10}$, vivimos las transformaciones en la educación; como la obligación de todas las estrofas del himno nacional, del que había sido omitida una estrofa sobre los "valientes soldados" que en ese momento reprimían y asesinaban. Y la entrada permanente de militares en las escuelas y la obligatoriedad de educación militar de los jóvenes. También nos privaron del paso más corto para llegar a la escuela, por aparecer muertos en un terreno baldío al lado de la cárcel de presos políticos conocida como los tres álamos, actualmente allí funciona el Servicio Nacional de Menores. Tengo grabada la imagen de una mujer con el cráneo triturado con una piedra; marcas que quedan en los niños que nos animan a trabajar por una cultura de paz, a otros los condenan en la continuidad de la violencia e injusticia. Los docentes eran obligados a cumplir con los mandatos del gobierno militar, allí, habían rostros tristes y seguramente dramas de muertes o desaparecidos en el silencio. Pelo el silencio se vuelve cómplice de la injusticia, y eso debe superar el educador.

Mis lecciones, de esta época de niñez, son que el docente requiere estar preparado para entender y enfrentar las diferencias entre niños, sus vivencias, en un sentido de respeto con el ser y entes, como la clave de entrada para alcanzar la anhelada cultura de paz. También, está llamado a demostrar autoridad para enseñar responsabilidad, valor que requerimos rescatar en la sociedad. Así también valorar la escuela desde el voluntariado representa gratitud para la sociedad que nos forma como ciudadanos, la recompensa resulta el propio desarrollo del ser. Pero ante todo debe mantener su integridad para defender la democracia y la justicia.

\section{La importancia de la familia en la formación del ser}

9 Gobierno Socialista de Salvador Allende que duró desde el 03 de noviembre del 1970 hasta el 11 de septiembre del 1973 .

10 Dictadura de Augusto Pinochet, que duró 17 años y se inició con una junta de cuatro miembros el 11 de septiembre del 1973.

Para el docente es fundamental conocer la constitución familiar de los niños y no tan 
niños, son años que marcan al futuro adulto. Las huellas familiares por su existencia o carencia nos moldean, allí aprendemos los valores que regirán nuestras vidas.

La gran escuela es la familia, fui influenciada por la buena familia que me tocó, la creatividad, mente inquieta y confrontadora de mi madre normalista, "Piense antes de hacer las cosas! ¿Cómo cree usted que se hace? Aprenda a hacer para valorar el trabajo de otros, hasta para "mandar" hay que saber hacer". Ella un ser influenciado por Piaget y Paulo Freire, y las ideas de izquierda de la UP, la hicieron una mujer moderna para la época que no tuvo muchas oportunidades de elección profesional. Hoy digo, que mi madre con posibilidades de estudios avanzados hubiese sido una gran ingeniera mecánica, por su lógica y capacidad resolutiva en asuntos de esos. Tengo mucho de mi madre, mis hijas me lo recuerdan.

Al transpolar esos momentos de vida de mi madre, sin duda ella tuvo influencia de dichos autores. En las palabras de Pinto (2004) reconozco que mi formación tuvo en su origen influencia de Freire, que vivió del 1965 al 1971 en Chile, ejerciendo cargos públicos, entonces mi madre recibió algo de esos discursos en su quehacer educativo y político. Habla el autor sobre la influencia de Freire en la educación chilena, con algunas experiencias críticas e innovadoras en el sistema escolar, que resume en dos aspectos

1) El legado humanista de que por medio de la educación es posible luchar y tener la esperanza de transformar las relaciones de opresión, por otras que valoren la liberación y la convivencia más colaborativa entre los sujetos; y 2) El legado pedagógico de que nadie se educa solo, todos nos educamos entre sí, mediatizados por el mundo, que es natural y cultural a la vez. Es decir, mediante la pedagogía del diálogo y la pregunta es posible construir conocimientos más efectivos para la convivencia democrática (PINTO, 2004, p. 235).

Veo con claridad entonces el trabajo voluntario que conocí en aquella época, en respuesta a esa convivencia colaborativa entre los sujetos, así acompañé a mi madre a realizar trabajos voluntarios en fábricas abandonadas por sus dueños en tiempos de la UP, experiencia maravillosa que la recreo como un gran paseo. Por otro lado, veo en mi madre la práctica de la pedagogía del diálogo y la pregunta para construir conocimiento. Insistente en la pregunta para pensar y crear la respuesta, antes de la facilidad de 
una explicación por parte de ella; lo hizo con nosotras, con sus nietas y bisnietas. Hoy creo, que aun cuando ella no nos incitaba a que formuláramos preguntas de manera verbal, nos decía que siempre debíamos formularnos preguntas, como una forma concordante con lo que decía Freire al "insistir na necessidade de estimular permanentemente a curiosidade, o ato de perguntar" (FREIRE; FAUNDEZ, 1985, p. 27). En esa idea, es procurar una educación más de preguntas que dé respuestas como una manera de promover la creatividad y la capacidad humana de asombrarse, resolver problemas esenciales, promoviendo así el conocimiento.

Aclaro, que viví en una familia de abundancia femenina, con dominancia autoritaria en un sistema familiar matriarcal. Con todo su entusiasmo y amor por los niños, mi madre animó mi creatividad, las artes, la música y la poesía, escuchó a mi abuela recitar con su fuerte voz sus largas poesías con una memoria que fue lucida hasta sus 92 años. Así, como rehusar y no botar cosas que pueden ser útiles es una herencia que hasta hoy me persigue, practico la clasificación de residuos desde hace décadas.

Otro ser importante fue mi abuelo, influyó en la valoración de la vida y el respeto a ella; sus interesantes charlas sobre moral y ética, sobre la convivencia perfecta de las hormigas y el trabajo perfecto de las arañas, analogías que nunca olvidaré. Sus compañeras de trabajo en los telares eran las arañas, una vez nos regaló huevos de arañas para que habitaran en la casa, mi madre no lo entendió. Todo resultaba fascinante, cada momento con él fue importante. Aprender sobre administración personal del dinero, mis primeras clases de economía y ahorro; lecciones que me han permitido vivir bien, con prudencia. Su trabajo voluntario como bombero, fue admirable, hoy existe una sala de reuniones con su nombre en la Decimosexta Compañía del Cuerpo de Bomberos de Santiago ${ }^{11}$ que él fundó.

De las enseñanzas sobre el trabajo en equipo entre las hormigas y la administración, surgió mi primera experiencia de liderazgo, formé un club de juego destinado a comprar pelotas y cuerdas entre un grupo de niños, porque no teníamos individualmente como hacerlo. Los organice para que entregáramos una parte de las mesadas de cada uno, así reunir suficiente dinero para la compra de nuestros juegos. Un éxito, logramos tener una pelota y cuerdas, todos colaboramos y logramos jugar felices.

Entonces mi madre al igual que mi abuelo, estaban allí enseñándome a observar, como leer de la vida en cada cosa. Ahora me encuentro con Freire (1991) cuando dice que "La vuelta a la infancia distante, buscando la comprensión de mi acto de "leer" el mundo particular en que me movía" (FREIRE, 1991, p. 1), posiblemente, sea cuando haciendo
11 Referencia encontrada en https:// www.decimosexta.cl/nuestracompania/fundadores 
y viendo hacer aprendió el significado del acto de percibir. También, desde allí, entiendo el voluntariado como una forma de crear conciencia colectiva, de ser parte de esa sociedad colaborativa, con sentido de pertenecimiento en los espacios donde se comparte y se trasciende.

\section{Jugar a ser maestra y mucho más}

Enseñar puedeser un acto de entretenimiento, para quedar grabado en la memoria; nunca tenemos que olvidar que dentro del ser, sin importar la edad, existe el niño que corrió con sus mejillas saladas de sudor y tierra, así rebosaba la alegría.

Transcurrió mi infancia en el juego de ser "maestra", igualmente rígida y castigadora, mi hermana fue la víctima en mis primeros pasos como educadora. Permanentemente hacer escuelas o jugar a ser científica. Crear un laboratorio donde realicé experimentos, como elaborar un filtro de agua; más adelante preparar brebajes, mirar insectos, operar un pollo, sembrar y un sinfín de juegos que me enseñaban. Pienso que jugar fue maravilloso siempre, realizar actos familiares, cantar, bailar, elevar volantín, jugar metras (bolitas), manejar bicicleta, jugar a las escondidas, con las manos, con las sombras, figuras de papel, entre tantas cosas que puedo releer en mis recuerdos. Jugué, y jugué mucho, mi hermana fue fundamental en eso; tuve muñecos hasta adolescente y mis últimos muñecos los entregue a mis nietas.

Pero el juego no era parte de la escuela, nos robaban la esencia de ser niños. No tengo en la memoria un evento de juego en mis años de formación. Sin embargo, en esa época Gabriela Mistral ${ }^{12}$ estaba presente con su poesía y enseñanzas pedagógicas en la educación chilena, en sus rondas y canciones populares en los juegos de niños que recuerdo

Dame la mano y danzaremos; dame la mano y me amaras. Como una sola flor seremos, como una flor y nada más...

Décadas más tarde saldría a relucir el juego en mi vida como docente en agronomía, creo también que la esencia del amor y la unión que expresa Gabriela Mistral. Tengo como práctica mejorar las actividades de enseñanzaaprendizaje que utilizo. Entre ellas una relacionada con el rally y el debate ${ }^{13}$, que mis estudiantes disfrutaban, según las evaluaciones realizadas a las prácticas pedagógicas. Un estado de ánimo de agrado y alegría, son emociones que
12 Poetisa y educadora chilena, primera latinoamericana que ganó el premio nobel de literatura en el 1945. http:// www.memoriachilena.gob.cl/602/w3article-3429.html
13 Documento disponible en las
memorias de la IV jornada de
investigación educativa en la UCLA.
https://www.ucla.edu.ve\%2Fviaca
dem\%2Fredine\%2 Fjornadas\%2FM
emorias\%2520IV\%2520Jornadas\%
2520 ode $\% 2520$ Investigacion $\% 2520$
$2008 \% 2$ FR-O20\%2520 Memorias.
doc\&usg=AOvVaw1FAOxmsIjNOU-
Ocicmvu2r 
favorecen el aprendizaje; un rally aumenta la adrenalina que es la hormona moduladora de los procesos de aprendizaje y memoria. También en otros espacios, comunitarios y de docentes, desarrollé actividades contextualizadas con juego de roles. En el campo, las demostraciones y simulaciones han sido mi herramienta de interpretación ambiental, para la concientización.

Ahora pienso que el docente, en la disciplina que sea, requiere recordar los juegos, para crear, para variar, para innovar en sus prácticas pedagógicas. El juego $\mathrm{y}$ el entretenimiento, requieren estar presente en la enseñanza; jugar es fundamental para el desarrollo del ser humano del futuro, nos socializa, nos da habilidades para trabajar en equipo, nos ejercita y nos hace creativos. Tristemente y con indignación vemos a los niños actuales adormecidos en sus juegos electrónicos, sin relacionarse con el mundo físico real.

\title{
El desciframiento de la palabra fluía naturalmente de la "lectura" del mundo particular
}

\begin{abstract}
Leer con entendimiento, es un acto que los docentes tenemos que rescatar en la formación de seres críticos e integrales, independientemente a la disciplina que se imparta. Comprensión de lecturas, no es memorizar ni repetir, es relatar las esencias sometidas al juicio de los valores y principios que nos rigen.
\end{abstract}

El amor a la lectura, lo heredé de mi padre ausente en lo cotidiano, sus momentos en el hogar eran (aún son) prioritariamente en su sillón leyendo y estudiando. Mi forma de encuentro con él siempre ha sido la lectura, hoy mis poemas y lecturas espirituales. Su excesiva responsabilidad con el trabajo, me hizo pensar por muchos años que amaba lo que hacía; pero en fin, fue la única oportunidad de estudio para él, que trabajó desde los ocho años. Recreo sus historias de los días de su infancia sin madre, rodeado de naturaleza y vida simple, en la lejanía de la civilización, como mi sueño de vida. Esa trasmisión cultural de lo rural en su vida lo practicaba en sus fines de semana sembrando hortalizas en el patio, allí yo presente. Recuerdo ver las acelgas, los tomates, papas y ajos creciendo, luego cosechando. Eran tiempos de crisis y escasez en UP, acompañados de mis primeras clases de agricultura urbana.

En el escrito de Freire (1991) sobre "La importancia del acto de leer", refiere dos formas con las cuales me identifico plenamente; leer el mundo desde la observación con las palabras y leer las palabras para conocer el mundo. 
Pero antes de conocer este pensamiento, conté como mi madre y mi abuelo, me inculcaron la observación del mundo, y en este ejercicio de palabras sobre mi vida me encuentro con el educador popular que recuerda su acto de leer el mundo desde la observación y las palabras, "En este esfuerzo al que me voy entregando, re-creo y re-vivo, en el texto que escribo, la experiencia en el momento en que aún no leía la palabra" (FREIRE, 1991, p. 1).

En este revivir, veo con indignación la salida de un país por la misma causa, una dictadura, décadas después geográficamente inversas (Chile, 1977 - Venezuela, 2018). En días pasados viví el placer nostálgico de caminar por las calles de mi infancia y esa diminuta casa que veía tan grande, así son las perspectivas en la temporalidad. Allí recibí a mis nietas, nieto e hija, para iniciar su nueva vida alejada de su tierra, así como yo hace 42 años atrás llegue a Venezuela. Esas pequeñas, parte de mi existencia, ahora ocupan el mismo espacio de mi infancia. Juntas comimos los damascos y granadas que sembramos en familia cuando era niña. Y como dice Freire, "Allí reencontré algunos de los árboles de mi infancia. Los reconocí sin dificultad" (FREIRE, 1991, p. 4). Algo hermoso de sembrar es cosechar, no importa quién ni cuándo, en esta ocasión es mi hija, son mis nietas, en años pasados fueron otros. Hoy en nuestra casa en Venezuela son mis vecinos, con los cuales siempre compartí de los frutos de la agricultura urbana. Así creo que es el resultado del acto de educar, no veremos muchos de sus frutos, pero están en algún lugar.

En este releer y revivir mis recuerdos, veo con la curiosidad aprendida, pero también con la lectura y escritura que encontré a mi corta edad. Con el mayor placer de mi niñez y juventud la lectura fue mi gran compañera, que me alejó de la vida normal de esas etapas; mis hijas hoy me dicen "mamá tu no eras normal". Leer cuentos clásicos, leer obras de drama, romance, suspenso, ciencia ficción, política, ciencia... Mafalda de Quino ${ }^{14}$, cuanto disfruto sus comic. De cada obra me formaba imágenes, emociones e historias que vivía, lloraba, reía o me indignaba. En el año 1974 tuve mi primera experiencia de expresión literaria, gané un concurso de composición sobre la historia de Chile, el premio fue el libro La cabaña del Tío Tom, un cuaderno y un lápiz.

Me esforzaba, me esfuerzo, en la comprensión crítica como la clave sobre la importancia del acto de leer que habla Freire. La lectura parece una herramienta lógica en la educación, pero creo que en ocasiones no es considerada como parte fundamental en la formación del ser integral crítico, veo con tristeza como se le resta importancia. Ya en mi adolescencia leer era un acto extraño, de los libros que pidieron estudiar en educación media fuimos pocos
14 Joaquín Salvador Lavado Tejón o Quino (Mendoza, 17 de julio de 1932) es un humorista gráfico e historietista argentino. Su obra más conocida es la tira cómica Mafalda, conocida como una niña preocupada por los problemas del mundo, con varios personajes donde se muestra un humor ácido e incluso cínico $\mathrm{y}$ ahonda con frecuencia en la miseria y el absurdo de la condición humana. 
los que realmente los leíamos. En una ocasión, tercer año, pasaba las horas libres en la biblioteca con mi amiga Celi, decidimos leer los cuentos de Las mil y una noches. En la universidad, era una de las pocas que visitaba la biblioteca, incluso tenía carnet ${ }^{15}$ de la biblioteca pública que usaba. Para estudiar algún tema revisaba tres textos y triangulaba la información, hábito que aún me enfrenta con el tiempo, cuando me sumerjo en otras cosas que me persuaden. El libro más interesante, creo que el único, como obra completa que me pidieron leer en la universidad, fue "Las formas ocultas de la propaganda" de Vance Packard, la hegemonía presente en cada espacio de la sociedad de consumo y manipulación de masas. Por cierto, recordando, la profesora de la disciplina de comunicación social era brasileña. Hice un trabajo profundo, que en aquella época uní mi análisis crítico con la formación política que recibía, obtuve la máxima calificación.

La lectura crítica tendría que ser una práctica en todas las disciplinas, me recuerdo hasta leyendo las historias del álgebra de Baldo. En mi vida docente cambie mis hábitos de lectura, me hace falta mis lecturas de antes, ahora los contenidos académicos me invaden y la vista no me ayuda; leo y mucho, artículos y trabajos de los estudiantes. En la práctica pedagógica, siempre incorporó la lectura, pero con un sentido de libertad en la elección; es tanta la producción de conocimiento, que enfocar la enseñanza en una literatura específica no lo comparto. Entender el mundo, es quizás un reto imposible de alcanzar. Mientras más entramos en la sociedad del conocimiento descubrimos lo ínfimo del que poseemos. Leyendo a Freire (1991), pensaba ¿Qué diría de tantos avances científicos, que ponen en tela de juicio tanto conocimiento preestablecidos como verdades, tanta historia dada como cierta que se tiene que rehacer?. Entonces traigo estas palabras que comparto con Freire "[...] en la medida en que fui penetrando en la intimidad de mi mundo, en que lo percibía mejor y lo "entendía" en la lectura que de él iba haciendo, mis temores iban disminuyendo. (FREIRE, 1991, p. 3).

En el "entendía", me encuentro yo, porque hoy pienso que de todo nuevo descubrimiento quisiera leer e interpretar la vida. En ese océano vertiginoso de conocimientos, abundante y complejo, a cada generación le será más desafiante entrar en él sin confundir sus pensamientos, por lo contrario, permitiendo dar claridad a las ideas. Lo contextual será cada día más certero y el pensamiento globalizante más inalcanzable. Entonces es nuestro mundo el que estamos llamados a entender, a cambiar, compartir con respeto, y debatir en las diferencias. Se han cometido tantos errores por transpolar teorías, en agricultura, construcciones, hábitos, economía, entre otras
15 Documento de identificación que permitía el uso de la biblioteca. 
cosas. Retomando la lectura, creo entonces que el docente requiere buscar estrategias motivadoras para que los alumnos lean, pero primero es él quien debe enamorarse de la lectura. Como dice Freire, además de lo mágico de la lectura, hay que tener presente la necesidad de "[...] educadores y educandos de leer, siempre y seriamente, de leer los clásicos en tal o cual campo del saber" (FREIRE, 1991, p. 3).

Aun cuando no he trabajado en el área de las lenguas, creo que mantengo esa sensación de molestia por encontrar tantas limitaciones en la lectura, comprensión de escritos e interpretación de las palabras por parte de los alumnos. Al respecto comparto con Freire que leer de manera crítica es un acto político. Por eso como práctica pedagógica, en mis áreas de agroecológica y educación ambiental, asignaba la interpretación de notícias agrícolas o ambientales, con las cuales traspasamos el conocimiento con discusiones dialógicas donde emergían posiciones políticas y soluciones creativas. Por eso alfabetizar requiere ser un acto liberador.

En tal sentido mantengo mi crítica a cómo se han conducido los programas de alfabetización, en el caso de Venezuela con la llamada misión Robinson ${ }^{16}$, que a diferencia de lo que dice Freire en el sentido de la significación existencial del alumno y no del educador, llegó cargada de intereses partidistas. Al final aprendieron a escribir sus nombres en listas para ser manipulados con fines electorales y partidistas; sin apostar como dice Freire a "prácticas claramente políticas de movilización y de organización" lo que podría constituirse en un instrumento para una acción contra hegemónica. Ocurrió todo lo contrario, fue el sentido de fortalecer un sistema claramente hegemónico con la manipulación de las masas. Esta y otras misiones permitieron ir subiendo falsamente los índices de desarrollo humano del país, con cifras que no miran la calidad y sentidos de fondo de las mismas. Pero este es otro asunto de gran amplitud que discutir.

Detrás de las palabras objetivas, está la interpretación con algún grado de subjetividad que manifiesta el conocimiento previo, el temperamento, valores y creencias, incluso el estado de ánimo. En esa subjetividad desde mi adolescencia, por releer eventos, paisajes o sentimientos, comenzó a emerger la poesía. Pensando quizás en esa faceta de mi ser, por la esencia espiritual que evoca mi nombre Rayen, recreo a mi abuela materna; una mujer admirable con su don histriónico y oratoria de largas poesías, que mantuvo con alta lucidez hasta sus 92 años. La poesía ha sido algo muy cerrado en mí ser, algunos supieron sobre mi gusto por la poesía en el sepelio de un amigo guitarrista (al cual no fui), donde mi madre recitó mi poesía "Enamorado del cuerpo de mujer" (2006). Luego
16 La misión Robinson es un programa social del gobierno nacional venezolano de Hugo Chávez, para enseñar a leer y escribir a la población analfabeta venezolana, con materiales de educación distintos a lo habitual y elaborados en Cuba. 
de eso, solo he publicado 2 poemas: "Tierra de bondades" en mi libro "Técnicas Agroecológicas para el Semiárido"17, y la otra "Valle del Turbio" en un boletín de la universidad. Luego ellas, las poesías, también comenzaron a ocupar un espacio en mis actividades de educación ambiental, allí realice poesías a cada árbol, sobre ideas pedagógicas y a lugares que visitaba para dar conferencias. La poesía resulta un ejercicio académico interesante para la expresión. En ese transitar realice una compilación de algunas decenas de poemas que edité para mi padre en el año 2007.

La TV o el cine también son herramientas que han sido de influencia en quienes somos, así como el incontrolable uso actual de las redes sociales. En mi infancia tuvieron una influencia muy puntual, pero sin duda de importancia para mi vida, fueron programas como: El Mundo Submarino De Jacques Cousteau y Topo-Gigo. Respectivamente estos programas educativos acompañaron mi pasión por la naturaleza en su complejidad (Sería Bióloga Marina!!), y curiosidades por la ciencia. Mis libros de cabecera, fue una serie llamada Naturaleza, los amaba.

En la actualidad, en esta revolución de la comunicación pareciera que menos dialogamos, tenemos que respirar profundo y avanzar con ellos, aun cuando nos comprendamos menos. Así decía Freire en sus cartas pedagógicas publicadas en el 2012, en estos tiempo tan diferentes a los nuestros, los docentes requerimos tener presente, "[...] la capacidad crítica, nunca adormecida, siempre atenta a la comprensión de lo nuevo" (FREIRE, 2012, p. 36). En esa comprensión crítica "[...] que nos permita defendernos de las fuerzas alienantes" (FREIRE, 2012, p. 138), así como muestra Jerzy Kosinski en el año 1970 el poder de la televisión en la novela "Desde el Jardín”. Creo que los filmes, programas o redes sociales son buenas herramientas, que también he usado en las prácticas pedagógicas, no alcanzan el valor de un libro. La imaginación sobre los paisajes y las escenas de un libro son la película personal, es sin igual lo que un escritor nos transmite con las palabras.

Pareciera que se acrecientan las brechas generacionales, por eso los docentes hemos tenido que ir superando nuestras resistencia ante cosas que nos siguen pareciendo incomprensibles. En ese esfuerzo de buscar puntos de encuentro con estas nuevas generaciones, comencé a usar el cine como herramienta para recrear temas importantes en la discusión crítica. Acepté que el celular y las redes sociales son parte de la vida actual, y me arriesgue como dice Freire (2012) a entrar en el mundo de las aulas virtuales. Tenemos que estar preparados para todos esos avances a favor de la educación, invadir con nuestros sueños esos espacios donde violenta lo diabólico
17 Libro publicado en el 2007, 1000 ejemplares en papel. FUNDACITELara, CIARA y Editorial de la UCLA. Reseña en https://www.researchgate. net/publication/32936162_ Documentacion_de_informacion_en_ tecnicas_agroecologicas_para_las_ zonas_semiaridas_del_Estado_Lara 
y perverso que atrapa al futuro. Sin embargo, los padres tienen gran responsabilidad, requieren ser los dosificadores de los medios de comunicación en su contenido y calidad.

Entiendo que las nuevas formas de comunicación representan una fuente importante de conocimiento y motivación, de acercarnos a las diferencias y coincidencias en esa tarea de desarrollar la capacidad de aceptar la diversidad. $\mathrm{Y}$ en esa comunicación, resulta importante conocer historias de vida de los padres y de otros, como vivencias llenas de cultura, temporalidad, aciertos y desaciertos, las que escuché de niña están guardadas en mi mente. Esa puede ser, o es una de las formas como romper las barreras que actualmente existen, en lo que expresa Freire (2012) sobre la dificultad que existe entre las relaciones de padres e hijos. Hoy siento con alegría, en mis esfuerzos comunicacionales, cuando mis nietas me recuerdas; una dice que quiere ser jardinera como su abuela, la otra en la lejanía se acuerda de las semillas de calabaza que secaba para ella y comíamos juntas. En una oportunidad mi hija menor, altamente comunicativa, llegó de un encuentro con sus compañeros, me abrazó y dijo "mamá gracias por darme el hogar donde comparto contigo, que triste la vida de mi compañero el cual tiene como padres el dinero".

\section{Los cambios culturales y el ser político}

En mi percepción de cambios territoriales, veo mí ser político en transformaciones, comprensiones, contradicciones e indignaciones con la humanidad, en un sentido temporal de ella y la posibilidad de contribuir generacionalmente con un mundo mejor.

Entiendo que la vida no es neutra, porque hasta decir ser neutro determina la existencia los acontecimientos que nos rodearan, al respecto Freire (2012) decía "[...] nuestra presencia en el mundo, que implica elección y decisión, no es una presencia neutra [...]" (FREIRE, 2012, p. 39). Mi vida estuvo marcada por muchos cambios políticos, así como de ciudad y de país, que forjaron mi ser. Un cambio significativo de vida fue enfrentar un nuevo país, con una nueva cultura y una naturaleza exuberante, todo por una dictadura militar donde vivencié por primera vez la violación a los derechos humanos y los rostros grises en cautividad. Mi educación política estuvo influenciada por toda mi familia de izquierda, por la UP, por las canciones de Víctor Jara ${ }^{18}$ y Violeta Parra ${ }^{19}$; luego por la canción profunda de Ali Primera ${ }^{20}$ en sus tenores tropicales. Mi sensibilidad social crítica quedó marcada. Época de días grises bajo la
18 Cantautor chileno de música de protesta que fue asesinado por la dictadura en el estadio nacional en el 1973.

19 Cantautora de música de protesta y artesana chilena.

20 Cantautor venezolano de música de protesta. 
bota militar acabó con los ideales de un gobierno socialista triunfante por el voto de un pueblo, la cual hoy veo en la serie de errores que lo conllevaron a su fin.

En esa etapa de mi vida, cuando se forjaba mi ser sensible socialmente, recibí una lección de mi madre, ser pobre no tiene que ver con indignidad, la visita a una "callampa" (favela o barriada) fue una experiencia significativa, que valoro. Por eso hoy, puedo decir que muchos de mis buenos momentos los he vivido en casas humildes, en paredes de barro, al compartir lo "poco" con alegría, con enseñanzas y aprendizajes.

Mi infancia fue la época de observar y escuchar, pero cuando llegué a mi nueva patria, comenzando la adolescencia me volví un ser crítico en la palabra, sobre injusticia, despilfarro, populismo y corrupción de un gobierno tropical. Para ese momento cayó en mis manos un libro que me fortaleció en las críticas al sistema de gobiernos en Venezuela, "Cuatro crímenes, cuatro poderes" escrito en el 1979 por Fermín Mármol León, dicho libro fue catalogado de best-seller. Al entrar en mi juventud fui formada ideológicamente por el partido, lo que venía escuchando por años se transformó en mis lecturas, Marx, Engels, Lenin, Allende, Fidel y Ho Chi Minh, y las revistas soviéticas sputnik, entre otras tantas. Esta educación, es parte de mí ser social, no fue la escuela ni la universidad. Fueron actividades de solidaridad por presos políticos en Chile, y la lucha contra las dictaduras, fueron murales de la corriente Brigada Ramona Parra ${ }^{21}$, fueron marchas, discursos y huelgas de hambre.

La decepción sobre historias leídas, sobre todo tipo de sistema de gobierno comenzó en el 1991 luego de leer el libro La Perestroika de Mijaíl Gorbachov editado en el 1987. Comencé a sentir los abusos de los gobiernos, corruptos y populistas, que mantenían el discurso de repartir migajas a un pueblo sumiso y manipulado. La verdad es que un tiempo caí en un letargo de mi existencia política, solo me enfrentaba a los grupos radicales de la universidad ante sus actos violentos. Luego creí en un cambio para Venezuela, en mi primera oportunidad de ejercer el voto, pero nos equivocamos. Después de 20 años los resultados son un país destrozado en la dimensión social, económica y ambiental, incoherente con los discursos de cuidadores del patrimonio de la humanidad. Hoy me declaro incrédula antela "buena" intención de todo políticoy por ende partido, me sentí identificada con el discurso inicial sustentado en el libro iIndignaos! por Stéphane Hessel que leí en el 2011. Entonces recreo la letra de una canción de Violeta Parra “... no sé por qué mi Dios regala sombrero con tantas cintas a quien no tiene cabeza", donde expresaba su indignación ante tanta injusticia social generada por unos pocos.
21 El muralismo social y la identidad comunitaria: dinámicas de relación y significación cotidianas. (1990-2009) Natalia Pinochet Cobos y Profesor Guía: José Luis Martínez C, Universidad de Chile. Disponible en: http://repositorio. uchile.cl/handle/2250/109858 
En definitiva, es casi imposible negar el ser político en el acto educativo, seriamos farsantes, hipócritas en dar teorías sin profundizar en la raíces de los hechos que determinan la realidad sentida. Para mi cada aula se transforma en un acto político, porque comparto que como docente "La lectura nueva de mi mundo demanda igualmente un nuevo lenguaje, el de la posibilidad abierta a la esperanza" (FREIRE, 1997, p. 81) que cree en la posibilidades de cambio generando diálogos críticos sobre las injusticias. Fui confrontada por más de un alumno indiferente o incómodo con hechos conflictivos que surgían en las discusiones de aula; en ocasiones mi inspiración fue tan lejos que los alumnos terminaban de pie aplaudiendo y nombrándome en cargos públicos. Es que hablar de agroecología y ambiente son dos mundos donde la política es inevitable; y en ellos como dice Freire hay oprimidos, ya sea: por los sistemas de consumo; de producción en monocultivos como agronegocios; por la falta de servicios básicos; o por los sistemas mineros depredadores, entre otras formas.

La formación política es esencial, sin llegar a influir en la educación con ideologías como líneas únicas de pensamiento, que de eso se encargue cada partido en sus espacios sociales de lucha para ganar adeptos. El pensamiento universal, diverso, es lo que debemos mantener en respeto a las diferencias. Se requieren ciudadanos con pensamiento crítico, así como sensibles social y ambientalmente. En relación a eso, Freire y Faundez (1985) nos hablan de la necesidad de concretar las acciones comprometidas de los educadores en los proyectos político-pedagógicos para generar reflexiones que den paso a la consolidación de cambios. Así, "[...] em todo esse processo político um trabalho pedagógico quase sempre invisível, altamente importante. Trabalho a ser aproveitado na transição em que se começa um esforço de sistematização da nova educação (FREIRE; FAUNDEZ, 1985, p. 49).

\section{Espiritualidad: amor, felicidad y paz}

Es que el amor, como máxima expresión de la existencia nos conecta a nuevos estilos de vida donde el perdón es caminar, el sentido de libertad esta tallado en la mente y el corazón nos lleva a luchar cada día en paz contra la opresión, con fuerzas que se renuevan en la fe.

Hacer las cosas con amor, con pasión, es fundamental; estas fuerzas humanas intrínsecas nos hacen educador para la transformación del ser, del mundo. En este sentido 
comparto los planteamientos de Freire en que la expresión de la humanidad se alcanza al salir del estado de opresión, y esa humanidad se logra accionar con pasión por lo que se hace, expresado en amor, coherencia y compromiso con la construcción de un mundo mejor. Y es ahí, en esa humanidad, donde lo intangible como el amor logra un estado de espiritualidad que nos permite expresar la esencia en acciones del cotidiano. En este punto que no profundizaré, haré un breve recuento porque lo considero importante en la vida del ser educador, como dice Freire "la educación es un acto de amor".

Catalogo mi vida espiritual en una búsqueda permanente con la raíz común de vivir el amor como esencia de la existencia, por lo tanto forma parte del ser humano y por ende de la educación como acto social. Crecí bajo lo que llamo catolicismo cultural, bautizos, primera comuniones, sepelios o matrimonios, dentro de un grupo que se autoproclamaba ateo, para el cual Jesucristo fue el primer comunista. Pero no hallé nunca sentido a lo que veía en esas religiosidades encontradas con el pensamiento político de que "la religión es el opio de los pueblos", dentro de mí sentía la necesidad de algo que fuera más allá. Entonces me encuentro con Freire (1997) cuando hace la crítica a la religiosidad que promueve una fe-sumisa, que necesita cambiar "[...] la visión de un Dios al servicio de los fuertes por un Dios al lado del cual debe estar la justicia, la verdad, el amor" (FREIRE, 1997, p. 114).

No estuve influenciada por religiosidad por parte de mi familia. Me tocó estudiar en un colegio de monjas que me hizo despertar mi espiritualidad, pero rápidamente fue cuestionado el catolicismo con sus ritos culturales sin verdadero sentido de amor. Me enseñaron a rezar, me resultó tedioso un sinfín de repeticiones sin sentido sincero. Luego busqué otro espacio católico donde me preparé para la primera comunión, allí me decepcionó la postura partidista frontal en un momento de elecciones. En esa búsqueda de mi ser espiritual tuve dos decepciones con el catolicismo. Dichos hechos me hizo apartarme completamente de las religiones, pero seguía o sigo en busca de esa conexión, donde el amor sincero es la máxima expresión. Para esa época, ya entrando en la juventud leí las novelas Siddhartha y Lobo Estepario de Hermann Hesse, que me conectaron espiritualmente en aquel momento con el budismo. Hoy entiendo que la espiritualidad no es un factor derivado de la religión, sino de la conexión del individuo con la esencia del ser trascendente, en un sentido donde lo intangible toma un valor especial.

En este momento de mi vida, opino que la religión no debe formar parte de la educación, más si el sentido de las diferentes formas de vivir la espiritualidad, que comparten 
la esencia del amor como la clave de la paz y la felicidad individual, el respeto a las diferencias. Los que iniciamos una vida espiritual comenzamos a practicar los momentos reflexivos apartados de la cotidianidad, del mundo que nos oprime, a valorar el silencio que el mundo nos roba, nos ayuda a desconectarnos de lo material que nos ata, nos permite mejorar la relación con los otros en la realidad que compartimos. Nos hace más felices.

\section{No seré profesora de matemáticas, la naturaleza me cautiva}

Disfrutar de lo que se hace y admirar lo que nos rodea son clave para la mejor praxis. Elegir una profesión resulta de una serie de factores como la vocación, temperamento, las experiencias de vida y circunstancias. Entonces encontré que educar me lleva a transformarme cada día al leer y releer la realidad que comparto y deseo mejorar; y en ese afán de entenderla valoro la interdisciplinariedad y complejidad.

Me gustan las matemáticas, siempre las vi fácil, no entendía como los demás no podían entenderla. Perdía la paciencia cada vez que me pedían que explicará matemática, entonces decía iJamás seré profesora! La lógica matemática es útil en la vida, muchos profesores la hacen ajena y complicada. Al respecto observé que la mayoría de los fracasos en la universidad son las disciplinas con número; la gente inicia una ingeniería, con un sentimiento encontrado con las matemáticas. Por no ser indiferente a lo que ocurría con los jóvenes que abandonaban los estudios superiores en los primeros semestres por causa de los números, entre otros consejos, les hablaba del condicionamiento neurolingüística ante lo esperado y ocuparse por superar las debilidades. Culturalmente hay una herencia de terror ante el aprendizaje de las matemáticas. Así, les decía que en las noches antes de dormir meditaran diciendo iLas matemáticas son hermosas, fáciles y útiles, amo las matemáticas!; también lo hice con mis hijas, hoy una de ella me dice que tengo influencia filosófica de Descarte. Es gracioso, pero verdad, luego de una formación ingenieril es difícil divorciarse de los números, mi mente los construye y los trae continuamente, en la diversidad de tareas cotidianas como explicaciones ambientales. Son parte del mundo aritmético que nos obliga a intercambiar el tiempo de nuestras vidas según valores monetarios, mi gran reto fue empoderarme del saber social.

En mi formación de educación media también viví la enseñanza de oficios que resultan "útiles" en la vida, como oportunidades de sobrevivencia, o como forma consciente 
para valorar los oficios de otros. En esta etapa aprendí mecanografía, taquigrafía y tejido a mano, antes ya había aprendido a tejer con un o dos palillos. En centros culturales recibí clases de dibujo, flauta (música), cuatro (instrumento típico de Venezuela) y fui parte de una coral, aun cuando tengo que reconocer que soy bastante sorda y con una voz nada agraciada. Creo que es interesante el rescate del conocimiento de oficios como parte del ser integral, que en la educación venezolana fue eliminada. Igualmente, importante es la enseñanza de las artes y música. Fortalecí dicha idea con el libro "La isla" de Aldous Huxley que me cautivó en un momento de mi vida, no comparto todos sus planteamientos novelescos basado en sus utopías sobre la vida, pero si en la oportunidad de los jóvenes de pasear por la diversidad de alternativas profesionales para elegir su futuro profesional. Las interacciones vivenciales con las diferentes opciones profesionales son importantes en la definición de una vida profesional, con un sentido de gusto y aporte a la transformación del mundo. Nunca estuvo en mí un sentido mercantilista sobre ser profesional.

Tampoco sería profesora de educación física ni inglés, dos áreas que fueron condicionadas, una por la dificultad corporal y otra por causa neurolingüística (anticapitalista). Mi madre vivió preocupada por mi estatura pequeña, a mí poco me afectó, sólo ante los retos gimnásticos que más que relacionarse con mi estatura era por cobardía. Por otra parte ¿cómo podía tener algún gusto por el inglés si me rodeaba de un pensamiento anticapitalista y anti gringos, simbolizado por la lengua inglesa? Muchas veces se desconoce cómo se marca la vida de los niños con nuestros discursos y preocupaciones. Traté de superar esto como madre, mis dos hijas hablan inglés e hicieron todas las acrobacias que yo jamás hice por temor.

La elección de una carrera universitaria ocurrió a mis 13 años, como dije anteriormente hasta esa edad sería Bióloga Mariana, luego conocí muchos profesores universitarios en la creación de la Universidad Experimental de los Llanos Ezequiel Zamora (UNELLEZ) ${ }^{22}$, fue una experiencia maravillosa. Conocí al equipo de biólogos que lograría describir luego a la mayoría de los peces de los ríos de Venezuela. Muchos profesores eran extranjeros, entre ellos pude aprender de forraje y microbiología. Comenzó el conflicto de mi futuro profesional, palabras que marcan. Recuerdo de la voz de uno de los biólogos como si fuera hoy iEl futuro del país está en la diversidad de peces de los ríos y allí el de los biólogos! Entonces comencé a amar la agronomía, por aflorar mi cobardía ante las Rayas de río y Caribes (Pirañas) en aguas turbias; temor que surgió por la gran cantidad de cuentos populares sobre dramáticas muertes y amputaciones. Decidí ser agrónomo, me gradué de ingeniero agrónomo en la Universidad Centroccidental
22 Aun cuando la universidad fue creada en el 1975, nuestra llegada a Venezuela y a Guanare específicamente fue en el 1977, estaba en construcción la sede en esta ciudad http://www.unellez.edu.ve/ portal/ 
Lisandro Alvarado (UCLA), luego de un sinfín de paros universitarios, que en muchas ocasiones me desanimaban.

Durante los dos últimos años, de formación como ingeniero, trabajé como auxiliar de laboratorio en el postgrado de horticultura en el área de poscosecha. En el momento del egreso muchos pensaron que me quedaría cursando maestría, sin embargo recibí un excelente consejo iEjerce la profesión antes de elegir un postgrado! Sin duda fue excelente el ejercicio profesional en campo, el cual ya venía en una relación directa con la agricultura por parte de mi familia y la decisión personal de haber realizado pasantías (que para la época no eran obligatorias). Concluyó, por la experiencia de vida, que ejercer la profesión y realizar pasantías es fundamental en la formación profesional, nos permite asumir una postura crítica ante el área de formación; asunto que fue fundamental en mi quehacer docente en el Decanato de Agronomía de la UCLA y mi participación en la comisión de currículo.

En el camino al postgrado en la UNELLEZ encontré la Educación Ambiental (EA) y la agroecología, mis áreas de ejercicio profesional que me dan esencia, puedo concluir que esta universidad marco mi vida. Las circunstancias de vida nos ponen en el camino correcto, conocí la EA justo en el momento de iniciar una maestría en suelo, a causa de iniciarme como docente de EA en una universidad privada donde duré 20 años. La EA comenzó a ocupar todos los espacios donde me accionaba, en un primer momento mi tesis se enfocó en productores agrícolas y manejo integrado de plagas, una experiencia de extensión que terminó en una ruptura con mi tutor. Una pausa luego del conflicto, mi vida cambio, me ocupé en abrir mi mente a la dupla que desde ese momento hasta la actualidad continúa activa, agroecología y educación ambiental. Luego me vi realizando una tesis con campesinos que estaban ocupando áreas protectoras de una cuenca hidrográfica, fue tan inspirador que elaboré un cuento para niños La historia de una cuenca que logró dos ediciones (1999, 2000).

Mi vida académica se inició con la extensión y se mantiene con ella; años después abrí mi trabajo a la gestión ambiental universitaria y formación ambiental de profesores, allí logré realizar mi tesis doctoral en educación ambiental. Pero sin duda mi acción permanente ha sido la extensión, donde logró integral actividades de investigación y docencia, en esa trilogía de la cual mucho se habla y poco se avanza.

\section{La "extensión" o mejor dicho el diálogo de saberes: educación popular}

Cuando comparto con otros me siento viva, allí tengo la oportunidad de entrar en la 
profundidad del reconocimiento de otros en sus realidades. Cada momento me enseña y me permite abrir mi mente a la diversidad de pensamiento, circunstancias que determinan la historia, el ahora y el futuro.

Quizás el encuentro más significativo con Freire lo tengo con mi trabajo en "extensión", que inicié en el 1993 cuando cursaba mi magister en Educación Ambiental, término que cuestioné en muchos momentos. Hoy comparto con Freire (1973, p. 25) que "[...] claramente, el concepto de extensión no corresponde a un quehacer educativo liberador [...]" sino a una entrega de un conocimiento que alguien cree que otro necesita. Aún usamos académicamente la palabra extensión, porque no hemos ganado la discusión dentro de las rígidas instituciones universitarias, pero es un debate que se ha dado y requiere continuar. He asumido la práctica con una concepción diferente a dominación o transferencia tal como lo señala Freire. En ese contacto con otros fuera del recinto laboral, hay un proceso de comunicación bilateral, un diálogo de saberes donde se confronta y complementa práctica y ciencia. Y digo ciencia porque ellos tienen la teoría de sus prácticas, aun cuando desconozcan autores, porque son ellos los productores de dichas teorías. Hay que reconocer que mucho conocimiento se ha perdido.

Mi primer juicio fuerte, a la formación como ingeniero agrónomo que recibí, fue al cuestionar la teoría sobre extensión que recibí en la universidad (sin práctica). Esto ocurrió luego de comenzar a vivir actividades de campo con mi estimado profesor Adolfo Cardozo y su Doctora Gallina ${ }^{23}$ (naciendo en aquel momento). Al interactuar en esos dinámicos convites, como él llama, me sentí estafada por todas esas aburridas clases que recibí en la universidad de típica educación bancaria como dice Freire. Es que la repetición de teorías no es efectiva para aprender, como lo es hacer y entender lo que se hace. Entonces comenzó mi transformación en mi esencia tímida con la labor social maravillosa de mi maestro Cardozo, que me abrió la puerta al conocimiento de la agroecología y a una educación ambiental popular desde el diálogo de saberes. Lo cierto es que cada vez que tengo un encuentro con otros, en el espacio que sea, se da de manera natural un intercambio de conocimientos que no puedo frenar, que me nutre como el río al mar. Fue mi momento de conectar el conocimiento sobre control biológico de plagas, que tanto me había gustado en la Universidad, con la agroecología y la salud del planeta.

Las vivencias son fundamentales, es lo quehoy señalan como aprender haciendo. Mi primera experiencia como profesional del agro, antes de Cardozo, iba cargada con la ilusión de practicar el control biológico de plagas, allí tuve
23 Profesor Jubilado de Ingeniería en Producción Animal en la Universidad Experimental de los Llanos Ezequiel Zamora, su presentación disponibles en su canal https://www.youtube.com/ watch?v=zqkJfKJrF9Y 
mi primera experiencia como educadora popular. Luego de un diálogo de oposición con un grupo de trabajadores agrícolas, enseñé con una demostración práctica sobre la inocuidad de los controladores biológicos. De tal manera, lograr que participaran y se comprometieran con nuevas prácticas y conceptos de salud integral, control biológico, y decirle no a los agrotóxicos. Allí se mezcló, como dice Freire, el sentido humanista y científico, entre las concepciones de salud y amor propio de esos trabajadores con la complejidad de los procesos naturales en desequilibrio dentro de un monocultivo y aplicación de venenos. Fue un reto superado, generando un cambio de actitud laboral, con nuevos valores que fueron compartidos. En mis días laborales adquiría experiencia de relaciones humanas, enfrentando el reto de un mundo masculino, donde incomodaba con mi presencia.

En esa época (1996) me invitaron a dictar un curso de caña de azúcar (rubro que trabajaba) dirigido a productores de arroz y maíz, acepté el reto. Investigue la intención del gobierno local en ese sector para ofertar el curso; eran claros intereses de grupos de poder para someter a los productores. Necesitaban futuros suministradores de materia prima de lo que sería el central azucarero más moderno del país, sin análisis del impacto social que eso causaría. Di el curso con el contenido solicitado, pero les hablé de las ventajas comparativas entre lo que hacían culturalmente y la proyección del nuevo rubro como sistemas productivo, los llevaría a perder autonomía y disminuir las ganancias. Nunca más me llamaron para administrar un curso. El tiempo me dio la razón en relación a eso, al final hicieron que la gente sembrará y el central azucarero nunca fue terminado, ni en ese periodo que se inició ni cuando fue expropiado por el gobierno de Chávez ${ }^{24}$, los campesinos perdían las ganancias en el transporte de sus cosechas hasta otros centrales lejanos.

Mi verdadero aprendizaje sobre el diálogo de saberes ocurría con el profesorCardozo, cuandocomencéa participar de los proyectos en CENDI, y luego CENDI-PROGIS ${ }^{25}$, fue una escuela inolvidable de práctica y teoría en la realidad rural. Luego vino mi tesis de magister, con un programa de educación ambiental en cuencas hidrográficas que me permitió reflexionar sobre las "mejoras" territoriales, las problemáticas sociales y los programas de conservación. En la confianza con los campesinos uno descubría como eran utilizados por grupos de poder, explotados bajo modos modernos, toda ansia de poder económico superaba los intereses de construir un desarrollo sostenible. Aquí comencé a valorar más las culturas y tradiciones, a respetar y compartir, a entender y buscar confrontaciones, diálogos críticos para que ellos se animaran a transformar sus
24 Historia del Central desde la expropiación en el $2001 \mathrm{https}$ // elpitazo. net/sucesos/desfalco-la-mayor-centralazucarera-la-investigacion-persigue-alministro-adan-chavez/

25 Programa que se logró por el trabajo de CENDI, Centro de Investigación y Divulgación de Sistemas Sostenibles de Producción Agropecuaria. Disponible en https://adocardo.blogspot.com/p/ cendigranja.html 
realidades. En esta época leí muchos libros sobre desarrollo rural en Colombia que me abrieron a la crítica de los tantos fracasos en transferencia tecnológica, como resultados de investigaciones también fracasadas por fundamentarse en caprichos de investigadores, no en las necesidades de los productores ni con su participación. "Pero a esta consideración no subyace ningún arrebato falsamente humanista que pretenda negar la tecnología y la ciencia” (FREIRE, 2012, p. 137).

Después, como profesora en agronomía me enfoqué en el trabajo de "extensión" que no gozaba del reconocimiento académico debido, era o es la cenicienta del cuento universitario. Trabajé en la conformación de un Centro Demostrativo de Tecnologías Agroecológicas ${ }^{26}$ (CenecoAgro), orientada al manejo del territorio semiárido. Esta fue el aula ambiental que fundé y construimos conjuntamente con mi colega Merly Guillén y estudiantes; un espacio para enseñar y aprender sobre agroecología, donde compartimos 19 años de experiencias en lucha contra la desertificación. Fue una forma de sembrar la semilla en estudiantes de primer semestre, niños, comunidades, estudiantes de diversas instituciones que nos visitaban de varias partes de la región. Toda esta experiencia está repartida en diversas ponencias, vídeos, artículo y en el libro "Técnicas Agroecológicas para el Semiárido" que elaboré en el 2007. Pero lo más importante es que quedó en la formación de cientos de estudiantes. En esta reflexión decidí preguntarle a Esquilo Yépez exalumno que actualmente trabaja en Bolivia, ¿Qué significó CenecoAgro para ti?

Es la base de todo lo que es mi carrera profesora, desde los valores y principios en la profesión y la agroecología hasta el desarrollo personal con el compartir. Todo lo que aplico ahora viene de allí, hasta orientó en las ferias agroecológicas en las que participo y vivo en un condominio ecológico donde realizo el seguimiento ambiental a la laguna... su esencia quedó en cada uno de nosotros...

Aquí aprendí a valorar el conocimiento, creencias y mitos de todo aquel que compartió sus experiencias en CenecoAgro, en un constante diálogo de saberes. El Centro se nutría cada semestre de las actividades teóricoprácticas de los estudiantes; del trabajo voluntario de un grupo estudiantil que hacía vida en él (duró activo hasta el año 2014); de proyectos de investigación; visitas guiadas y trabajos de campo en comunidades.

Entre otras experiencias significativas me enfoqué con la participación de estudiantes en dos territorios, uno
26 Ponencia en el Libro de resúmenes del V Congreso Venezolano de Diversidad Biológica, celebrado en Zulia, en julio de 2014. CenecoAgro una mirada mitigante con perspectiva agroecológica, p: 116. https://issuu. com/ejercito.comunicacional/docs/ resumenes_pantalla_v5 
en el semiárido con artesanos de madera ${ }^{27}$ y el otro una cuenca hidrográfica ${ }^{28}$ con pequeños campesinos. En ambas tal como dice Freire, logramos en diversos encuentros problematizar sus realidades de manera objetiva, en territorios padeciendo de desertificación y erosión respectivamente, y consecuente pobreza.

Su práctica política le habrá enseñado que su futuro está en la transformación de un hoy perverso en el que él y sus compañeros y compañeras son casi cosa. Entiende así la problematización del futuro y no su inexorabilidad. Ese futuro no llegará si no hablamos de él al mismo tiempo que lo construimos (FREIRE, 1997, p. 33).

Allí la relación ser humano-naturaleza se entendía desde las tradiciones y los modos de sobrevivencia en un sistema de opresión. Logramos la concientización cuando, como dice Freire, (1973) se comprenden las interrelaciones de ellos en la complejidad de sus realidades, así asumieran con mayor prioridad aquello que no lo era. Sin embargo vi cómo, en ambos grupos, los pobladores fueron utilizados y manipulados políticamente con proyectos de gobierno que no cumplían con la liberación, pero si con la dominación ideológica asistencialista y populista. Allí actuaron con intereses partidistas a través de programas de extensión, persuadiendo y como dice Freire haciendo un campo propicio para su propaganda. Ellos cumplían con lo que el autor llama invasión cultural antidialógica que dice

La propaganda, las consignas, los “depósitos”, los mitos, son instrumentos, usados por el invasor, para lograr sus objetivos: persuadir los invadidos de que deben ser objetos de su acción, de que deben ser presas dóciles de su conquista. Es necesario que el invasor quite significado a la cultura invadida, rompa sus características, la llene, incluso, de subproductos de la cultura invasora... Como forma de dirigismo, que explora lo emocional de los individuos, la manipulación inculca, en ellos, la ilusión de actuar, o de que actúan, en la actuación de sus manipuladores... (FREIRE, 1973, p. 45).

Vi esas acciones extensionistas en ambas experiencias, siendo en la de artesanos al estilo de la novela de Gabriel García Márquez "La historia de una muerte anunciada", llenaron de populismo que atrajo oportunistas que se transformaron en esclavistas de los artesanos tradicionales (explicado en el artículo que refiero en el ítems 23 de pie de página). En la cuenca hidrográfica vimos que los invasores
27 Consideraciones sobre Ambiente Y Desarrollo. Caso de Estudio de La Artesanía En Madera De Guadalupemunicipio Jiménez Del Estado Laravenezuela. Disponible en la revista Compendium, 2010, p:5-22. https:// dialnet.unirioja.es/ejemplar/285298

28 Curso electivo en Ingeniería Agronómica, ofertado en el periodo 1999-2005, Educación Ambiental en la Gestión de Cuencas Hidrográficas, que fue administrado en trabajo continuo de campo en la Comunidad de Matatere en la zona alta de Río Claro del estado Lara. 
entregaron una serie de rubros a los campesinos, que ellos desconocían culturalmente. Por tanto, en conversación de los estudiantes con los campesinos surgió el deseo de conocer sobre el consumo de los rubros desconocidos, así se logró aportar conocimientos culinarios para el consumo de los mismos. Como resultado comenzaron a consumir berenjena; de la soya aprendieron sus formas de procesamiento y extracción de leche vegetal, con el tiempo ellos decían que sembraban la vaca. En otra oportunidad contaron sobre la pérdida de la cosecha de bananas, entonces promovimos un intercambio de saberes de campesino a campesino, aprendieron a realizar licor de cambur y consumir la concha de los plátanos. Fueron intercambios maravillosos, de sabores, risas y compartir, luego enterarnos de la embriaguez colectiva con el vino realizado.

Descubrí, en esta época, la incapacidad de los profesionales en realizar trabajo interdisciplinario y de las instituciones en realizar trabajo interinstitucional, el protagonismo casi siempre es el ganador. A pesar de ello, logré alianzas importantes con profesionales de ciertas áreas para el desarrollo de CenecoAgro con ingeniería civil, medicina, veterinaria, economía, suelo, control biológico, arte, entre otras; pero siempre sentí la necesidad de mayor integración. Siento que los obsoletos procedimientos académicos administrativos tienen alto grado de responsabilidad para evitar la integración; la burocracia y espacios de poder nos carcomen. Una problemática histórica a la cual Muñoz (2019) señala en

La multiplicación de oficinas y la complejidad de la labor académica, por ejemplo en la investigación interdisciplinaria, han acarreado que el académico, además de profesar e investigar, tenga que llevar a cabo múltiples actividades que, finalmente, son exigencias resultado de decisiones que se toman en las oficinas de dirección administrativa, por la burocracia de alto y mediano niveles. Son actividades que la burocracia señala que no le corresponden hacer a ella, pero que son indispensables de realizar. $\mathrm{Al}$ académico le restan tiempo, pero no le cuentan en la medición del desempeño, así como tampoco se contabiliza el trabajo de campo en las ciencias sociales y en las humanidades (MUÑOZ, 2019, p. 86).

En la experiencia de docencia-extensión, durante varios años, logramos que los jóvenes que se iniciaban en la carrera de ingeniería agronómica realizaran contacto con comunidades rurales llevando algún aporte de 
conocimiento que ellos solicitaran. Era interesante porque las comunidades sabían claramente que eran jóvenes sin muchos conocimientos técnicos, que hacían esfuerzos por preparar información actualizada de especialistas para cumplir con las demandas de los grupos campesinos. Era entonces un diálogo de saberes, donde las comunidades asumían un rol de comprensión y apoyo a la formación de los jóvenes ante el esfuerzo que ellos realizaban. Y como dice Freire, (1973) se lograba entrar en las percepciones de los sujetos (estudiantes-campesinos) donde existen las representaciones culturales que condicionan las realidades concretas, dando apertura a una visión crítica que explica la razón de los hechos percibidos en dicha realidad. Allí también compartimos mitos y creencias que respetamos, abordando en otros momentos diálogos sobre conocimientos técnicos para explicar ciertas creencias, como el injerto de mango con piña que se cree popularmente.

Concuerdo entonces con Freire, (1973) que la experiencia surgía de las legítimas necesidades de ambos grupos: los estudiantes necesitaban conocer de las realidades agrícolas, y las comunidades rurales tenían curiosidades sobre temáticas específicas para transformar sus realidades. Fueron decenas de encuentros con diversos grupos. Durante este tiempo recibimos las opiniones cuestionadoras de colegas que nos llamaron irresponsables por llevar a esos jóvenes a realizar esas actividades comunitarias. Para la mayoría de los jóvenes fue una experiencia importante en su formación. Concluyó, por todo lo vivido, que la sensibilidad social no se alcanza por unas horas de servicio comunitario en los últimos semestres, sino por un continuo contacto con las realidades sociales. Digo entonces que la sensibilidad social, responsabilidad ambiental y la investigación requieren ser impulsadas a través de ejes transversales en la formación profesional, que estén presentes durante toda la carrera y la vida.

\section{La pregunta constante, la investigación como estilo de vida}

Mi mente se activa cuando se formula preguntas, es la fuerza para alcanzar conocimiento. Esta fuerza surge en la infancia con la curiosidad, por tanto tenemos la responsabilidad de mantener vivo ese ser curioso en el futuro profesional investigador.

Creo que aquí existe otro fuerte encuentro con Freire, (1985) la curiosidad que sembró mi madre la mantengo. Necesitaría muchas vidas para lograr responder y profundizar en tantas preguntas que me hago 
a diario, necesito horas del día, días en la semana para lograrlo. Según mi experiencia esto se logra valorando las capacidades del otro, enfrentándolo a la posibilidad de resolver, de no contar todo y esperar las preguntas, provocando el interés sobre cada cosa que se hace. Mis mejores docentes, los que me dejaron pensar. A mis hijas las incité a ser cuestionadoras, no muy favorable en la adolescencia, pero maravilloso para sus vidas. El trabajo investigativo y social requiere iniciarse con la curiosidad desde la niñez, y en la universidad requieren ser ejes transversales en todo lo largo de la formación profesional. La auto-formulación constante de preguntas, pensar el para qué, cómo, por qué, qué necesito, cuáles son las posibles dificultades, cómo enfrentar las dificultades, son algunas preguntas que requerimos formularnos a diario. Una vida sin cuestionamientos, sería una vida monótona sin transformación.

Entonces en la formación de ese ser crítico, como docentes tenemos la tarea de dejar de entregar un conocimiento rancio; necesitamos entregar lo que es inacabado, crear la curiosidad y la capacidad de investigación, y con ello la habilidad para acceder con juicio en la sociedad del conocimiento. Entiendo también que las teorías están sumergidas en la inconsciencia de aquellos que realizan la práctica a espaldas del conocimiento teórico explícito. Lo importante de hacerse consciente de las teorías es el reconocimiento del hacer, provocando fortalecer la llave entre teoría y práctica. En ese sentido, y por mi vida pragmática, activa por naturaleza, me fortalezco desde mi reflexión dialógica con Freire (1973) y encuentro que
Al hacerlo, lo que antes, tal vez, no concibiéramos como teoría de nuestra acción, se nos revela como tal. Y, si la teoría y la práctica son algo indicotomizable, la reflexión, sobre la acción, acentúa la teoría, sin la cual la acción (o la práctica) no es verdadera. La práctica, a su vez, gana una nueva significación, al ser iluminada por una teoría, de la cual, el sujeto que actúa, se apropia, lúcidamente (FREIRE, 1973, p. 43).

Para mí la investigación nació de la mano al trabajo en comunidades con sus habitantes, ambas se vuelven indivisibles en mi praxis. Aun cuando no puedo negar que fui formada en la investigación experimental. Ahora aprendo cada día de los contextos que tengo como oportunidad, donde se problematizan las realidades desde el pensamiento crítico, las diferencias culturales, los intereses sobre cada territorio y el sentimiento de amor expresado en múltiples formas. 
Es en el sentimiento de amor donde logramos encontrar lo que nos une, en un deseo de trascender en la existencia donde es posible conjugar la importancia de lo transgeneracional. Entonces nos enfrentamos al gran reto de alcanzar armonía en las diferencias, donde el rescate de valores para la convivencia es fundamental. El nuevo ser requiere encontrarse con sus raíces en la naturaleza y la espiritualidad, en el sentimiento de amor que nos permite reconocer al otro.

\section{Referências}

CONTRERAS, Rolando N. Pinto. Paulo Freire: un educador humanista cristiano en Chile, Revista Pensamiento Educativo. v. 34, p. 234-258, jun. 2004.

FREIRE, Paulo. Pedagogía de la indignación: cartas pedagógicas en un mundo revuelto. Buenos Aires, Siglo XXI Editores, 2012.

FREIRE, Paulo. A la sombra de este árbol. Barcelona: El Roure Editorial, 1997.

FREIRE, Paulo. La importancia de leer y el proceso de liberación. México, Siglo XXI Editores. 1991.

FREIRE, Paulo. ¿Extensión o comunicación? La concientización en el medio rural. Siglo XXI editores, 1973.

FREIRE, Paulo; SHOR, Ira. Medo e ousadia: o cotidiano do professor. Rio de Janeiro: Paz e Terra, 1986.

FREIRE, Paulo; FAUNDEZ, Antonio. Por uma pedagogia da pergunta. Rio de Janeiro: Paz e Terra, 1985.

GOODSON, Ivor. Hacia un desarrollo de las historias personales y profesionales de los docentes. Revista Mexicana de Investigación Educativa, v. 8, n.19, p. 733-758, sep.-dic., 2003.

MUÑOZ, Humberto. La burocracia universitaria. Rev. educ. sup [online]. vol.48, n.189, p. 73-96, 2019. 